\title{
Determination of Caffeine Content in Arabica and Robusta Green Coffee of Indian Origin
}

\author{
Luiza-Mădălina CARACOSTEA \\ PhD Student, IOSUD Carol Davila, Bucharest, Romania \\ Rodica SÎRBU \\ "Ovidius" University of Constanta, Faculty of \\ Pharmacy, Constanta, Romania \\ Florica BUŞURICU \\ "Ovidius" University of Constanta, Faculty of \\ Pharmacy, Constanta, Romania
}

\section{Abstract}

The coffee tree belongs to the Rubiaceae family, genus Coffea. Although more than 80 species of coffee have been identified worldwide, only two are economically important. Coffea Arabica, also known as Arabica coffee, is responsible for about $70 \%$ of the world coffee market, and Coffea Canephora or Robusta coffee represents the rest. Due to the strong physiological effects of caffeine on human physiology, the caffeine content is a very important quality parameter of processed coffee. Routine analysis of caffeine in the food industry can be facilitated using fast and reliable tests. In this article, we quantitatively determined the caffeine content using the chloroform isolation method and we also performed the qualitative determination of caffeine in green coffee of Indian origin by the UV-VIS spectrophotometric method. Following the analysis of caffeine isolate with chloroform, we obtained a caffeine content of $182 \mathrm{mg} / 100 \mathrm{~g}$ for the Robusta green coffee sample and $154 \mathrm{mg} / 100 \mathrm{~g}$ for the Arabica green coffee sample. Thus we can confirm the presence of a higher caffeine content in the Robusta India green coffee sample than in the Arabica India green coffee sample. In the spectrophotometric analysis we used 4 coffee samples obtained by extraction with hot distilled water and by extraction with cold distilled water. The spectral analysis confirms the presence of caffeine in both studied coffee species and agrees with the data in the literature.

Keywords: caffeine, green coffee, Arabica, Robusta, clorophorm, UV-VIS. 


\section{Introduction}

Studying the impact that coffee exerts on human health is of great interest, since coffee is one of the most commonly consumed beverages in the world, accounting for $75 \%$ of the regular soft drinks consumption [Toci, A., 2016]. Drinking coffee has frequently been discouraged, due to the risks associated with the excessive consumption of this beverage (hypertension, coronary heart disease, anxiety, insomnia, depression, osteoporosis, anaemia, pregnancy-related problems [Nawrot P., 2003]. Nevertheless, the more recent information about coffee phytochemistry and biological properties has progressively led to consider coffee as a potential functional food, as its benefits on human health seem to outdo its negative effects [Messina, G., 2015]. Specifically, experimental and epidemiological studies have demonstrated that coffee (and some molecules contained in coffee beverages) can provide beneficial effects against several pathologies, among which neurological diseases (Parkinson's and Alzheimer's diseases), cancer (breast and colon cancer), psychoactive responses (alertness, mood change) and metabolic disorders (type 2 diabetes). Moreover, in recent years, the beneficial properties of green coffee for human health have been pointed out, leading to a increase in the consumption of green-coffee-based beverages [Ludwig, I. A., 2014].

Coffee species are grown in almost all countries along the equator. The people involved in the cultivation of this plant have a long history of production and an important role both in the global market and in the field of research. Coffee beans are successfully used in food, cosmetics and pharmaceuticals due to caffeine and high polyphenol content. However, the most well-known and studied phytochemical compound found in coffee is caffeine. Although other alkaloids, such as theophylline and theobromine, are also present in coffee, caffeine is found in much higher concentrations. Caffeine can also be obtained from cocoa beans, tea leaves, kola nuts, guarana fruits. Depending on the source, it has different names. Thus, the caffeine obtained from coffee and kola nuts is called caffeine; from tea it is called theine; from the red seeds fried by Paullinia cupana is called guarana [Bușuricu F., 2020].

More than 80 coffee species have been identified worldwide [Clarke, R. J. 2003], only two are economically important. Coffea arabica, also known as Arabica coffee, is responsible for approximately 70\% of the global coffee market, and Coffea Canephora or Robusta coffee (commercial name of one of the main C. Canephora cultivars) accounts for the rest.

The Arabica plant is a descendant of trees native to Ethiopian coffee and is usually a large shrub that can reach a height of 4 to 6 meters. Its fruit, which has a fine, mild, aromatic taste, accounts for about $70 \%$ of world coffee production, and Arabica coffee usually has the highest prices on the market. The Arabica plant reaches maturity in 3 to 4 years and continues to bear fruit for 20-30 years. It requires a mild climate, ideal with temperatures between 15 and $23^{\circ} \mathrm{C}$ and rainfall of about 60 centimeters per year. The best Arabica coffees come from plants grown at altitudes between 2,000 
and 6,000 meters. The ideal altitude in this range varies with the distance from the equator [Smith B., 2006].

The Robusta plant is similar to Arabica in size, shape and time to maturity, but produces smaller and rounder grains. Robusta plants are cheaper to grow because they are more resistant to disease and can withstand warmer climates (preferring temperatures between $23^{\circ} \mathrm{C}$ and $30^{\circ} \mathrm{C}$ ). However, Arabica is much preferred over Robusta because its taste is considered superior [Farah A, 2017].

When they reach maturity, coffee trees of any kind usually bear fruit called "cherries" which turn red when ready for harvest. Arabica berries usually ripen in about 9 months, and Robusta needs 10 or 11 months. Coffee beans are the seeds of these cherries.

The main objective of this article is to offer many new opportunities and challenges for physico-chemical studies to analyze the main natural source that contains caffeine, namely green coffee belonging to the species Arabica and Robusta. In order to analyze and quantify the main component of green coffee, namely caffeine, we performed the following analyzes:

Sample preparation involves several steps, such as grinding, extraction of target compounds, pre-concentration and purification of the samples;

Isolation of caffeine with chloroform from the Arabica and Robusta green coffee sample of Indian origin;

Spectrophotometric determination of green coffee extracts in order to quantify the purine alkaloid - caffeine.

\section{Material and Methods}

\section{Preparation of coffee extracts}

The same batch of coffee was used for all extractions (100\% Arabica - India; 100\% Robusta - India). Each packet of coffee beans ( $250 \mathrm{~g}$ ) was opened immediately before brewing to avoid oxidative damage. The beans were ground using a professional coffee grinder (DIP Grinders DK-30). The coffee was ground "coarsely" for all extraction methods: hot extraction and cold extraction.

Extraction with hot distilled water: To prepare the hot coffee extract, the distilled water was heated to $80 \pm 2{ }^{\circ} \mathrm{C}$ in a heat-resistant beaker and the green coffee sample was placed in the beaker and the infusions were heated on the water bath for 5-7 minutes under continuous stirring. The sample to solvent ratio was $1: 20(\mathrm{~g} / \mathrm{mL})$. The aqueous extract was hot filtered through filter paper to remove insoluble particles. The aqueous extract obtained with hot water was named CA1 and CR1, respectively.

Extraction with cold distilled water: The cold preparation method was performed at room temperature (ranging from $21^{\circ} \mathrm{C}$ to $25^{\circ} \mathrm{C}$ during the experimental period). The coffee extract was prepared using a ratio of 1:10 (g ground green coffee / mL 
distilled water). The cold drink was extracted under static conditions. Ground green coffee and water were in contact for 24 hours in the refrigerator $\left(2-8^{\circ} \mathrm{C}\right)$. When the extraction was complete, the maceration was filtered through a paper filter. The aqueous extract obtained with cold water was named CA2 and CR2, respectively.

Chemicals: magnesium oxide; buffer solution: $\mathrm{pH}$ 6; metabisulphite of $\mathrm{Na} 0.5 \%$ solution; chloroform, caffeine standard were from Sigma - Aldrich.

\section{Work equipment:}

VWR UV-6300PC Double Beam Spectrophotometer;

Analytical balance;

Usual laboratory utensils and glassware

\section{Caffeine isolation with chloroform}

Due to the strong physiological effects of caffeine on human physiology, the caffeine content is a very important quality parameter of processed coffee. Routine analysis of caffeine in the food industry can be facilitated using fast and reliable tests. In this article, we quantitatively determined the caffeine content using the chloroform isolation method.

The caffeine isolation procedure was performed according to a method described by Buşuricu [Buşuricu F., 2008, 2020], with some modifications. The caffeine concentration was calculated according to the following equation:

mg caffeine / gram of coffee $=\frac{\left(A_{1}-A_{2}\right) \times 10}{0.410 \times m \times V}$

where:

$A_{1}=\frac{\left(A_{250}-A_{296}\right)}{2} ; A_{2}=\frac{\left(A_{250}-A_{296}\right)}{2} ;$

$10=$ the volume of the solution used in the experiment;

0.410 = absorbance value for $1 \mathrm{mg}$ caffeine;

$m=$ the mass of the sample;

$V=$ the volume of extract used in the determination;

$A_{1}$ și $A_{2}=$ absorbance values at wavelength $\Lambda 273$ for solutions 1 and 2 .

Working technique

Solution 1: weigh $1 \mathrm{~g}$ of each sample: green Arabica coffee and green Robusta coffee; bring in a heat-resistant glass, add $1.5 \mathrm{~g}$ of magnesium oxide in each glass corresponding to the sample I noted glass A (Arabica coffee) and glass R (Robusta coffee), and $75 \mathrm{~mL}$ of hot distilled water. The formed suspension is boiled for 10-12 minutes under continuous stirring. Filter the suspension obtained under low pressure by washing the filtrate several times with hot distilled water until a volume 
of approx. 80-90 mL of each sample. The solution obtained is brought into another heat-resistant glass, boiled for 5 minutes, cooled and brought into a $100 \mathrm{~mL}$ volumetric flask and made up to the mark with distilled water. From these extracts we bring in two $50 \mathrm{~mL}$ volumetric flasks a volume of $10 \mathrm{~mL}$ solution $\mathrm{A}$ and $10 \mathrm{~mL}$ solution $\mathrm{R}$ in which we add $5 \mathrm{~mL}$ of buffer solution $(\mathrm{pH}=6)$ and $10 \mathrm{~mL}$ of sodium metabisulphite, brought to the mark with distilled water , and these will represent S1A and S1R.

Solution 2: An amount of clear extract, equal to that taken for the previous solution $(10 \mathrm{~mL})$, is placed in a separatory funnel and 5 extractions are made with $15 \mathrm{~mL}$ of chloroform. The chloroform solutions are removed and the aqueous solution is transferred to a heat-resistant beaker, the funnel is rinsed with distilled water and added to the solution in the beaker $(25 \mathrm{~mL})$. Bring to the boil, evaporate, cool and place in a $50 \mathrm{~mL}$ volumetric flask. Fill with distilled water to the mark, and these will represent S2A and S2R.

\section{Identification of caffeine in Arabica and Robusta green coffee by UV-VIS spectrophotometric methods}

Ultraviolet / Visible Spectroscopy (UV-VIS) is an important analytical technique because it can be used to identify certain functional groups in molecules, but it can also be used as a test method. The method is quick and simple and allows us to confirm the presence of caffeine in CA1, CA2, CR1 and CR2 extracts. UV-VIS spectrophotometric measurements were performed at room temperature, using a UV-6300PC VWR Spectrophotometer at a wavelength range of 200-400 nm.

\section{Working method:}

Absorption of UV-VIS measurements were performed on VWR UV-6300PC Double Beam Spectrophotometer at 200-400 nm, using halogen and deuterium sources for visible materials and ultraviolet radiation, at a controlled temperature of $25^{\circ} \mathrm{C}$, using square quartz tanks with an optical trajectory of $1 \mathrm{~cm}$. The determination of the molar extinction coefficients of caffeine at $272 \mathrm{~nm}$ was performed by applying the known Bouguer Lambert-Beer law, by linearly mounting the dependence of the absorbence on the sample concentration. The measurements were performed in triplicate and the error associated with the concentration was the standard deviation obtained.

Preparation of the standard solution: For the preparation of the standard solution, the commercial chemical standard of caffeine was used and dissolved in distilled water according to the solubility procedure of F.R. X of the monograph Coffeinum. Weighed $0.5 \mathrm{~g}$ of pure caffeine which was dissolved by heating in $45 \mathrm{~mL}$ of distilled water. The solution obtained is cooled to room temperature and made up with the same solvent to $50 \mathrm{~mL}$. 


\section{Results and Discussions}

\section{Caffeine isolation with chloroform}

The caffeine concentration was calculated according to the equation presented, and the results were expressed in mg caffeine / gram of coffee.

Arabica green coffee $=\frac{(1.24-0.6065) \times 10}{0.410 \times 1 \times 10}=\mathbf{1 . 5 4} \mathbf{m g}$ caffeine $/$ gram of coffee suitable for $154 \mathrm{mg} / 100 \mathrm{~g}$ coffee

Robusta green coffee $=\frac{(0.98985-0.24745) \times 10}{0.410 \times 1 \times 10}=\mathbf{1 . 8 2} \mathbf{~ m g}$ caffeine $/$ gram of coffee suitable for $182 \mathrm{mg} / 100 \mathrm{~g}$ coffee

The graphical representation of the caffeine content by chloroform extraction for the Arabica and Robusta coffee samples is shown in Fig.1.

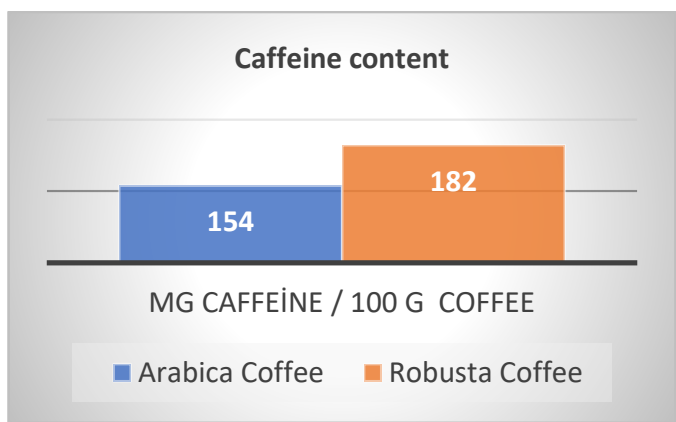

Fig. 1. Determination of caffeine content in Arabica coffee and Robusta coffee (mg caffeine / 100 g coffee)

C. Arabica and C. Robusta species differ in many ways. As the name suggests, Robusta coffee trees are more robust; that is, they are stronger, more resistant to pests and diseases, and less demanding than Arabica trees in terms of climate. Robusta coffee also contains higher amounts of antioxidant compounds and caffeine. The concentration and biological activity of caffeine depends on the following factors such as: processing conditions, agricultural practices (traditional or organic), the ideal growing climate, duration and storage conditions, and the origin of the coffee. According to the data presented in Table 1 [Smith B., 2006], the highest amount of caffeine by weight and variety is found in blueberry beans in Tanzania, with $1.42 \mathrm{~g}$ of caffeine per kilogram of coffee. Using the recommendation of the American Specialty Coffee Association with $10 \mathrm{~g}$ of ground coffee per $17 \mathrm{oz} \mathrm{(6} \mathrm{oz)} \mathrm{serving,} \mathrm{Tanzania}$ Peaberry would produce approximately $142 \mathrm{mg}$ of caffeine per serving of coffee. Other high caffeine coffees include Columbia Supremo, Columbia Excelso and Indian Mysore (1.37\% each), Kenya AA (1.36\%) and Costa Rica Tarrazu (1.35\%). At the other end of the scale with a lighter amount are Mocha Mattari (1.01\%) and Zimbabwe $(1.10 \%)$ coffees. In addition, the thickness of the grind also affects the caffeine content of the finished coffee. 
Table 1. The amount of caffeine after the coffee mixture [Smith B., 2006]

\begin{tabular}{|l|l|l|l|l|l|}
\hline Coffee source & Caffeine & Coffee source & Caffeine & Coffee source & Caffeine \\
\cline { 3 - 5 } & content & Content \\
Varieties & Varieties & $\begin{array}{l}\text { Dark mixes and } \\
\text { frying }\end{array}$ & $\begin{array}{l}\text { content } \\
\%\end{array}$ \\
\hline $\begin{array}{l}\text { Brazil } \\
\text { Bourbons }\end{array}$ & 1.20 & Kenya AA & 1.36 & $\begin{array}{l}\text { Colombia } \\
\text { Supremo Dark }\end{array}$ & 1.37 \\
\hline $\begin{array}{l}\text { Celebes } \\
\text { Kalossi }\end{array}$ & 1.22 & Kona Extra Prime & 1.32 & $\begin{array}{l}\text { Frying } \\
\text { Espresso }\end{array}$ & 1.32 \\
\hline $\begin{array}{l}\text { Colombua } \\
\text { Excelso }\end{array}$ & 1.37 & Mexico Pluma Altura & 1.17 & Frying French & 1.22 \\
\hline $\begin{array}{l}\text { Colombia } \\
\text { Supremo }\end{array}$ & 1.37 & $\begin{array}{l}\text { Mocha Matari } \\
\text { (Yemen) }\end{array}$ & 1.01 & Frying Vienna & 1.27 \\
\hline $\begin{array}{l}\text { Ethiopian } \\
\text { Harrar-Moka }\end{array}$ & 1.13 & New Guinea & 1.30 & Mocha-Java & 1.17 \\
\hline $\begin{array}{l}\text { Guatemala } \\
\text { Antigua }\end{array}$ & 1.32 & Panama Organic & 1.34 & $\begin{array}{l}\text { Decaffeinated: } \\
\text { All } \\
\text { mixtures }\end{array}$ & 0.2 \\
\hline $\begin{array}{l}\text { Indian } \\
\text { Mysore }\end{array}$ & 1.37 & $\begin{array}{l}\text { Sumatra process) } \\
\text { Mandheling-Lintong }\end{array}$ & 1.30 & & \\
\hline $\begin{array}{l}\text { Jamaican Blue } \\
\text { Mountain }\end{array}$ & 1.34 & Tanzania Peaberry & 1.42 & & \\
\hline $\begin{array}{l}\text { Java Estate } \\
\text { Kuyumas }\end{array}$ & 1.20 & Zimbabwe & 1.10 & & \\
\hline
\end{tabular}

According to the results obtained by the chloroform isolation method, the caffeine content is higher in Robusta green coffee (182 mg caffeine / 100 g green coffee) than in Arabica green coffee (154 mg caffeine / 100 g green coffee). these results can be correlated with data from the literature [Crozier T. W. M, 2012].

\section{Identification of caffeine in Arabica and Robusta green coffee by UV-VIS spectrophotometric methods}

The obtained spectra are shown in Fig. 2, 3, 4, 5 and 6. In Fig. 2 it is found that pure caffeine absorbs in the wavelength range between 220 - $350 \mathrm{~nm}$. Prior to spectrophotometric reading, CA1, CA2, CR1, CR2 extracts were dissolved in dichloromethane 25:25 (v / v) for better caffeine extraction from coffee. Extraction was performed 4 times with $25 \mathrm{~mL}$ of dichloromethane per round for each extract. Finally, the absorbance was measured with the VWR UV-6300PC Spectrophotometer in the range of 200-400 nm. According to Fig. 3 and Fig. 4. in the Arabica coffee samples CA1 and CA2 absorb caffeine in the range 220 to $350 \mathrm{~nm}$, but in the case of the extract obtained by the hot process, CA1, the maximum absorbance of 3.5 (u.a) is reached, while in the cold process, CA2, the absorbance 3.5 (u.a) is exceeded, reaching values of approximately 3.8 (u.a). According to Fig. 5., Fig. 6. in the case of Robusta green coffee extracts, the wavelength range in which it absorbs caffeine is the same as $220-350 \mathrm{~nm}$ and the caffeine obtained by both processes reaches a maximum absorbance of 3.5 (u.a). 


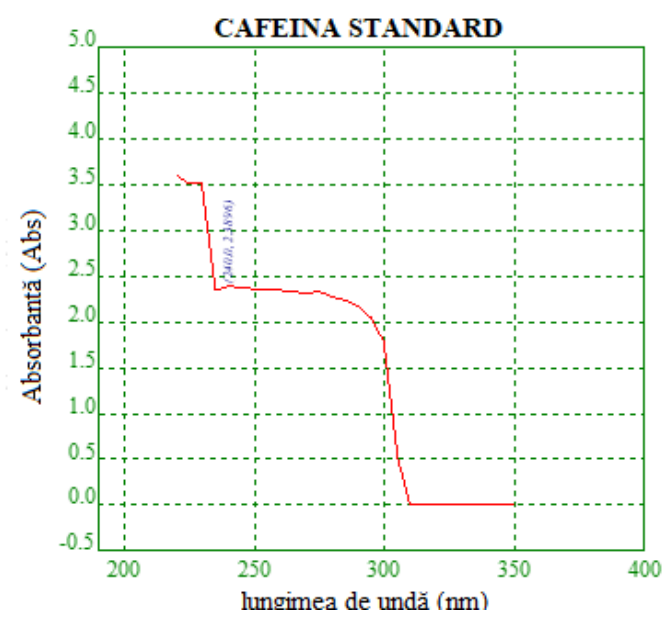

Fig.2. UV-VIS spectrum for standard caffeine

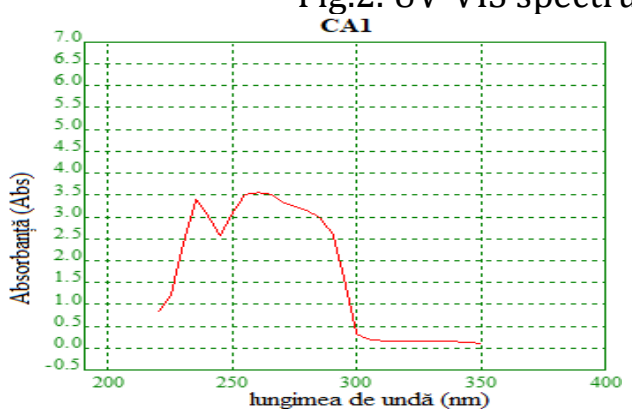

Fig. 3. UV-VIS spectrum for CA1 coffee sample

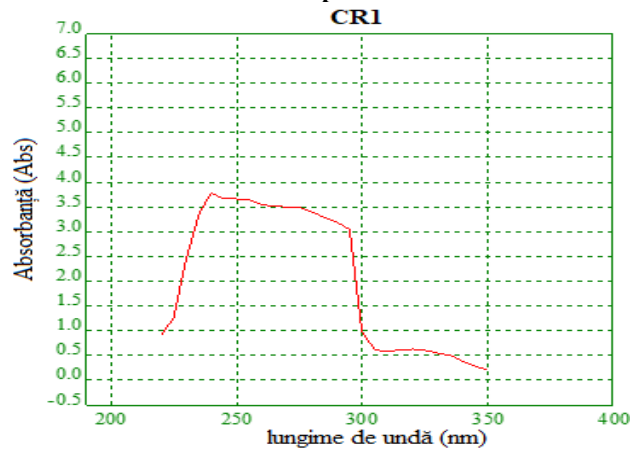

Fig. 5. UV-VIS spectrum for CR1 coffee sample

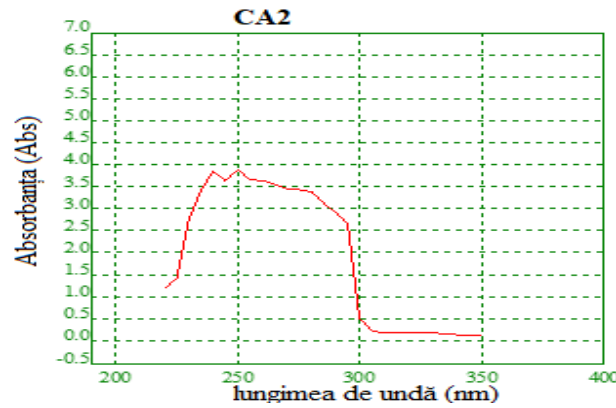

Fig. 4. UV-VIS spectrum for CA2 coffee sample

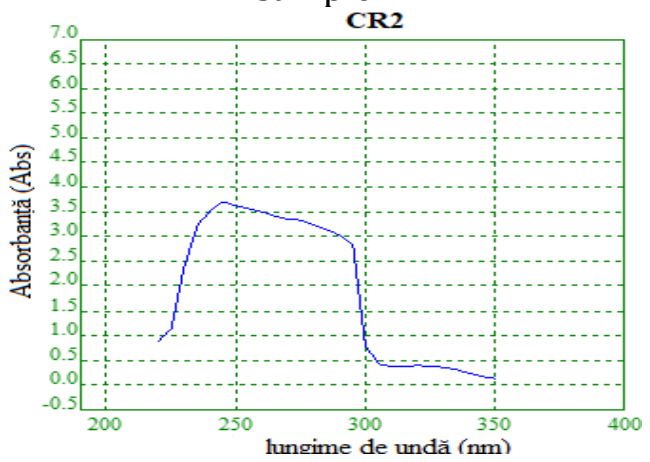

Fig. 6. UV-VIS spectrum for CR2 coffee sample

In Fig. 7., the spectrum of caffeine in Arabica green coffee extracted in water is presented and it is found that the intervals in which it absorbs caffeine are: 220-350. The maximum absorbance is ( $>4$ u.a.). In Figs. 8., the spectrum found in the literature is presented, namely the UV-VIS spectrum of caffeine in Arabica green coffee beans. 


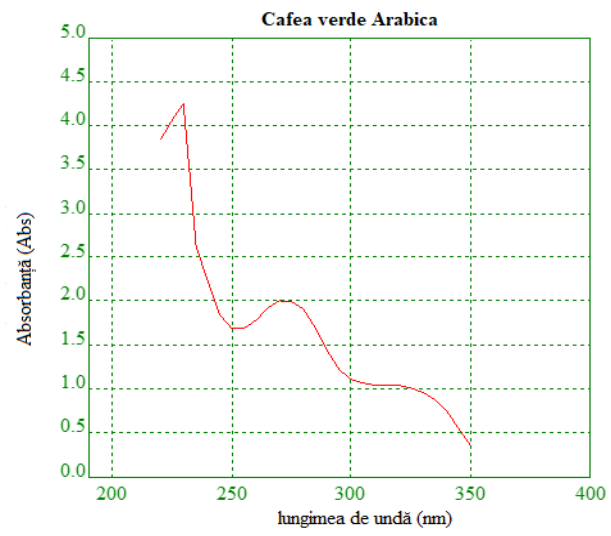

Fig. 7. UV-VIS spectrum for the Arabica coffee sample dissolved in water

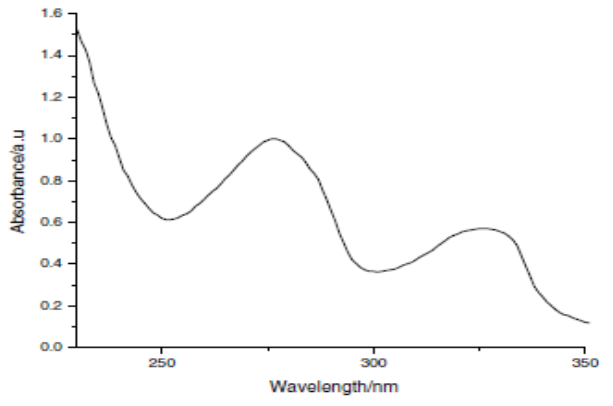

Fig. 8. UV-VIS spectrum of caffeine in Arabica green coffee dissolved in water

It is found that the extraction in water performed by us agrees with the data in the literature [Belay A,, 2008]. The differences between the spectra obtained depending on the analyzed coffee species, Arabica or Robusta are also due to the presence of other components in the coffee samples such as chlorogenic acids. Chlorogenic acids (CGAs) are classified according to the nature and number of cinnamic substituents and to the esterification position in the cyclohexane ring of the quinic acid. 5Caffeoylquinic acid is the most widely occurring and most studied CGAs. CGAs have antioxidant properties, whichplay an important role inprotecting food, cells, andany organ from oxidative degeneration and also the coffee plant against microorganisms, insects, and UV radiation [Global Coffee Market, 2017].

The method of preparation may also affects the composition of the final coffee extract. Although coffee is generally brewed with hot water, there has recently been an increase in the consumption of cold water coffee drinks in northern European countries, the United States and Japan, due to the new preparation methods involving longer extraction times at colder temperatures, rather than rapid exposure to high temperatures [13].

The method for the qualitative determination of caffeine in coffee can simply be applied quickly after the design of a spectrophotometer which, based on a simple analysis from the reading of the spectrum, indicates the concentration of caffeine. This method incorporates an additional advantage: it is based on the use of a UV-VIS spectrophotometer, being easy, fast and available today in most laboratories. Moreover, the application makes it easier to increase knowledge to identify caffeine in various green coffee and roasted coffee products.

\section{Conclusion}

The composition of green coffee has attracted interest as a potential source of beneficial bioactive -compounds, especially through the presence of caffeine. As the 
content of this alkaloid is affected by the processing conditions, the main objective of this article was to determine the caffeine content of two different species: Arabica green coffee and Robusta green coffee, both of Indian production. These species are considered the most important and most used worldwide, and different in many ways, including their ideal growth climate, physical appearance, chemical composition, and infusion characteristics made from green and ground seeds. Overall, the results of this research suggest that the natural source of green coffee, belonging to the Arabica species, is an important source of bioactive compounds and is characterized by beneficial properties, with a lower average caffeine content than Robusta coffee. This finding is interesting because Arabica coffee is the most commonly used in the preparation of beverages and the most commercially valuable, due to its aromatic superiority. In the Arabica and Robusta green coffee samples we quantitatively determined the main methylxanthine (caffeine) using the chloroform isolation method and we obtained a higher concentration of caffeine in the Robusta green coffee sample (182 mg caffeine / $100 \mathrm{~g}$ coffee) compared to the sample of Arabica green coffee (154 mg caffeine / $100 \mathrm{~g}$ coffee). Also from the spectrophorometric analysis we confirmed the structure and morphology of caffeine in the Arabica and Robusta coffee samples.

\section{References}

[1] Belay A., Ture K., Redi M. and Asfaw A., Measurement of caffeine in coffee beans with UV/Vis spectrometer, Food Chemistry, 2008, 108, 310-315.

[2] Bușuricu F., Anghel A. H., Margaritti D., Mititelu M., Schröder V. „Caffeine from energy products and interactions with some vegetable extracts”, Filodiritto editore - Proceedings, Nutrition, Diet Therapy \& Food Safety in the Context of the Covid , 2020, 19, 26-32.

[3] Buşuricu F., Negreanu Pârjol T., Chemical composition of roasted coffee and corresponding coffee beverages, Jurnal TMJ, (2008, 58 (2), 407-412.

[4] Clarke, R. J. Coffee: green coffee/roast and ground, Encyclopedia of Food Science and Nutrition, 2nd edition, Caballero, B., Trugo, L. C., Finglas, P., eds. Oxford: Academic Press; 2003, 3.

[5] Crozier T. W. M., Stalmach A. Lean M. E. J. and Crozier A.., Espresso coffees, caffeine and chlorogenic acid intake:potential health implications, Food Funct., 2012, 3, . 30-33.

[6] Farah A, Nutritional and health effects of coffee. In Achieving Sustainable Cultivation of Coffee, Lashermes, P., Ed.; Burleigh Dodds Science Publishing: Cambridge, UK,. 2017, 1-31.

[7] Global Coffee Market (2017): Global Industry Analysis, Size, Share, Growth, Trends, and Forecast 2017-2022. Available from: https://www.fiormarkets.com/report/global-coffeeindustry- in-depthinvestigation-and-analysis-report-36025.html 
[8] Ludwig, I. A., Clifford, M. N., Lean, M. E. J., Ashihara, H., \& Crozier, A. Coffee: biochemistry and potential impact on health, Food \& Function, 2014, 5(8), 1695-1717.

[9] Messina, G., Zannella, C., Monda, V., Dato, A., Liccardo, D., De Blasio, S., Valenzano, A., Moscatelli, F., Messina, A., Cibelli, G. The beneficial effects of coffee in human nutrition, Biology and Medicine, 2015, 7(4), 1.

[10] Nawrot P., Jordan, S., Eastwood, J., Rotstein, J., Hugenholtz, A., \& Feeley, M. Effects of caffeine on human health, Food Additives \& Contaminants, 2003, 20(1), 1-30.

[11] Smith B., Gupta U., Gupta B. S., Caffeine and activation theory: effects on health and behavior, Editor Smith B. and al.., CRC Press, 2006, 9-42.

[12] Toci, A. T., Farah, A., Pezza, H. R., \& Pezza, L. Coffee Adulteration: More than Two Decades of Research, Critical Reviews in Analytical Chemistry, 2016, 46(2), 83-92. 